\title{
“Torn between" Lines from a Working Mom's Dairy
}

\author{
Shylasree $\mathrm{TS}^{1}{ }^{10}$ \\ ${ }^{1}$ Department of Gynaecology Oncology, Tata Memorial Centre, Homi \\ Bhabha National Institute, Mumbai, Maharashtra, India \\ Ind J Med Paediatr Oncol 2022;43:10-11.
}

I was always in a state of dream during my teens and childhood,

went skipping to school without comparing my life with others.

The only dilemma in those days was to buy a flowery frock or a stripy one.

Sometimes I rebelled to have a fringe cut, but it was always bob cut!

I ate everything my mother cooked, most delicious and healthy food

Dad put in the culture of learning something new all the time.

We swam and climbed trees against norms of those days. I even rode a scooter and typed on a noisy Remington at lightning speed,

devoured everything my teachers taught,

some stern and some soft, but all kind and loving.

The only thing I complained in those days was mosquitoes singing in my ears

and there were many of them in my town.

After graduating to be a doctor, choices I made were not great master plans.

They were random heady thoughts and whispers from my heart,

some strong and some not so but no obsessions or compulsions.

Personal and professional spaces were separate and synched without complaints

like neatly stacked books in a library with a color code.

Time appeared unlimited, I never once looked at my watch with cool breeze touching the cheeks on sunset walks and starry nights.

Finally, managed to find love, maybe confused under the spell of hypothalamic-pituitary-ovarian axis!

DOI https://doi.org/ $10.1055 / \mathrm{s}-0042-1742640$. ISSN 0971-5851.
Address for correspondence Shylasree TS, MD, FRCOG, Department of Gynaecology Oncology, Tata Memorial Centre, Homi Bhabha National Institute, Mumbai, Maharashtra 400012, India (e-mail: shyla_sree@hotmail.com).

Finding wallpapers and cushions for the nest sounded fun, despite my partner's bored looks in shopping malls.

Two adults shared personal and professional space without short-circuiting each other, life sounded like frills without fuss.

Then, I ventured into an all-important journey without a map,

decided to take a well-trodden path all animal kingdom takes, "having babies!"

Nobody ever explained to me that this path was like walking in the snowy alps without a warm hoody or in a jungle without footwear.

Pregnancy kicks from inside the tummy were meant to be enjoyed,

but the tiny soft feet were getting bony and bigger by the weeks.

I slept on a king-size bed crosswise as little aliens with stinky diapers

climbed on it in the middle of the night from nowhere.

Dinner time was a long-drawn process of preparing foods of various consistencies

and ended in pasta and curry days, only cake days, and just take away chips!

Juggling ten thousand tiny jobs, my circadian rhythm would have suited planets

with longer than 24 hours to call it a day!

Life which was like classical physics once, nice and predictable,

became quantum science, with chaos and random tantrums,

not to be confused with premenstrual mood swings.

Everyone reassured that the results of such a journey are holistic and rewarding!!

At this stage, overwhelming thoughts entered my life (c) 2022. Indian Society of Medical and Paediatric Oncology. All rights reserved.

This is an open access article published by Thieme under the terms of the Creative Commons Attribution-NonDerivative-NonCommercial-License, permitting copying and reproduction so long as the original work is given appropriate credit. Contents may not be used for commercial purposes, or adapted, remixed, transformed or built upon. (https://creativecommons.org/ licenses/by-nc-nd/4.0/)

Thieme Medical and Scientific Publishers Pvt. Ltd., A-12, 2nd Floor, Sector 2, Noida-201301 UP, India 
which were not published in any journal medical or otherwise.

I confess, I had no guidelines with levels of evidence to clarify such thoughts.

Only soft conversations and deep breaths with women like me

when I met them hurriedly in the lift or car parks.

Hence, sharing hypothesis generating dilemmas and thought bubbles for future research!

- Do I breast feed long or just as long as maternity leave goes?

Immunity was not perfect science!

- Do I drive early to work before kids woke up or kiss them looking into eyes full of love?

Emotions of guilt are deep seated!

- Do I look after my sick child or my ill patients?

Duties have no boundaries!

- Do I write a scientific paper or paint with my toddler what looked like modern art?
Expression has no limits!

- Do I go part-time and exercise or work and earn security for my kids?

Time and retirement age are finite on earth!

- Do I attend a parent-teacher meeting or teach communication skills to my medical students? Charity begins at home!

Such dilemmas and many more went on and on for nearly two decades of my life!!

I was left with a sea of choices and no perfect answer. My head argued and heart tugged all the time, playing musical chair.

It was not "midlife crisis" or "burnout syndrome" reported in psychology.

No one had given a name to this universal feeling, which I constantly felt during the prime of my womanhood

and I called it "torn between,"

a chronic blissful state of tiredness and confusion. 